\title{
BMJ open Implementation of a low-budget, lifestyle-improvement method in an ordinary primary healthcare setting: a stepwise intervention study
}

\author{
Ann Blomstrand, ${ }^{1}$ Nashmil Ariai, ${ }^{1}$ Ann-Christine Baar, ${ }^{2}$ \\ Britt-Marie Finbom-Forsgren, ${ }^{1,2}$ Jörgen Thorn, ${ }^{1,2}$ Cecilia Björkelund ${ }^{1,2}$
}

To cite: Blomstrand $\mathrm{A}$, Ariai N, Baar A-C, et al. Implementation of a lowbudget, lifestyle-improvement method in an ordinary primary healthcare setting: a stepwise intervention study. BMJ Open 2012;00:e001154. doi:10.1136/bmjopen-2012001154

- Prepublication history and additional material for this paper are available online. To view these files please visit the journal online (http://dx. doi.org/10.1136/bmjopen2012-001154).

Received 19 March 2012 Accepted 13 July 2012

This final article is available for use under the terms of the Creative Commons Attribution Non-Commercial 2.0 Licence; see http://bmjopen.bmj.com

${ }^{1}$ Primary Health Care Unit, Department of Public Health and Community Medicine, Institute of Medicine, The Sahlgrenska Academy, University of Gothenburg, Gothenburg, Sweden ${ }^{2}$ Primary Care, Västra Götaland Region, Sweden, Sweden

\section{Correspondence to} Dr Ann Blomstrand; ann.blomstrand@allmed.gu.se

\section{ABSTRACT}

Objective: To evaluate, in an ordinary primary healthcare setting, the effects of a screening questionnaire and a self-administered health profile dealing with special reference to the involvement of motivated individuals in need of lifestyle changes.

Design: Intervention study in a naturalistic context, using a screening questionnaire offered to consecutive patients, followed by a self-administered health profile and a health dialogue.

Setting: Hisingen primary healthcare area (130 033 inhabitants), Gothenburg, Sweden.

Participants: Men and women aged between 18 and 79 , visiting any of the eight public primary healthcare centres (PCC) during an 8-month period, were presented with a screening questionnaire and, were offered, a health profile, a plasma glucose ( $\mathrm{p}$-glucose), blood pressure check and a health dialogue.

Main outcome measures: Motivation level, negative lifestyle factors in screening questionnaire and intraindividual changes in blood pressure, $p$-glucose, body mass index (BMI) and lifestyle factors between baseline and 1-year follow-up.

Results: Subjects with less favourable lifestyle and higher motivation chose to participate. A higher percentage of presumptive participants reported a less favourable lifestyle. The presumptive participants also indicated higher motivation. Participants showed more readiness to initiate lifestyle changes compared to nonparticipants $(p<0.001)$. At 1 -year follow-up significant reductions in BMI, waist circumference, waist-hip ratio (WHR), blood pressure and p-glucose were observed.

Conclusions: The results indicate that the method is on target and applicable to motivated individuals with a 'risk profile'. A pedagogical model including a selfadministered health-profile and a health dialogue, combined with emphasising the individual's own resources, seems to be a feasible method for effective preventive work in primary healthcare.

\section{BACKGROUND}

Over the last decade, our knowledge about the role of lifestyle in health outcomes has

\section{ARTICLE SUMMARY}

Article focus

- Simple screening questions in primary care can initiate motivation for lifestyle change.

- A self-administered health profile and a health dialogue can support lifestyle-improvement.

- A lean model for lifestyle intervention can be implemented in an ordinary primary care setting.

Key messages

- A pedagogic model engaging motivated individuals led to lifestyle improvement.

- A simple screening instrument caught individuals with less good lifestyle and readiness for change.

- Weight, BMI, waist circumference, waist-hip ratio, blood pressure and p-glucose were significantly improved after one year.

Strengths and limitations of this study

- A low budget method was broadly and successfully implemented in a naturalistic primary care context.

- A community based naturalistic study brings a randomised controlled study difficult to realise.

- The one-year follow-up results must be interpreted with caution because of absence of a parallel control group.

increased considerably. We are now aware that major public health problems such as diabetes, cardiovascular disease including stroke are associated with lifestyle. Physical inactivity is one of the greatest public health problems of our century. ${ }^{1}$ A sedentary lifestyle has become more common and is in itself a risk factor. $^{2}$ Body mass index (BMI) has increased among both genders and central fat distribution has become more common among women. ${ }^{34}$ An increasing incidence of diabetes has been reported among 50-year-old men in Sweden. ${ }^{56}$ Current national guidelines recommend lifestyle intervention for both primary and secondary prevention of major diseases 
such as diabetes, cardiovascular disease and stroke. ${ }^{7}$ Effective policies to promote healthy weight yield economic benefits. ${ }^{8}$ Negative stress has been reported as a growing health problem among women ${ }^{910}$ and reports of feeling stress more than doubled in the cohort recruited 2004, compared with that recruited 36 years earlier in 1968, in the Population Study of Women, in which secular trends in 38-year-old and 50-year-old women are studied. ${ }^{11}$ Furthermore, a strong association between physical activity and well-being was shown in the same population study and a positive change in physical activity was associated with increased well-being. ${ }^{12}$ From a population perspective low socioeconomic status is a risk factor and the greatest health benefits should consequently emanate from preventive work based in primary healthcare, in close cooperation with other public actors. ${ }^{13} 14$ 'High risk' and 'population-based' strategies should preferably be applied to primary healthcare patients. ${ }^{15}$ There is a need for simple instruments that provide more structure to preventive work at primary healthcare centres (PCCs), and that are suited to the primary healthcare context. Broad implementation within a given framework requires a structured and cost-effective strategy and education, in order to create uniform approaches.

The main aim of this study was to evaluate the feasibility of implementing a preventive primary healthcare programme consisting of a screening questionnaire and a self-administered health profile with special reference to involving motivated individuals in need of lifestyle changes. An additional aim was to evaluate the effects after 1 year in a well-defined, primarily urban population attending the primary healthcare.

\section{METHODS}

\section{Study population}

Hisingen, the fourth largest island in Sweden, has 130033 inhabitants and is located in Gothenburg, the second largest city in Sweden (493498 inhabitants at the start of the study in 2008). The demographics of Hisingen are representative of Gothenburg as a whole, with both highincome and low-income populations and high morbidity in some areas. The study population included men and women between 18 and 79 years of age who visited the eight publicly funded PCCs during a period of 8 months. The goal was to reach all patients attending the PCCs, including for acute disorders or for planned visits to general practitioners (GPs) or other staff. The study was carried out in a standard primary care context with an extra-resource of one health educator at each PCC and a process leader (first author).

\section{Instruments and assessment}

Waiting room screening questionnaire-intervention and assessment

The questionnaire used for waiting-room screening has been described in an earlier paper ${ }^{16}$ and represented the start of the intervention besides assessing self-reported lifestyle factors. It contains nine questions (with the possible responses yes, no, don't know) concerning lifestyle, one concerning heredity for cardiovascular disease, one question on readiness to start lifestyle change (with five response alternatives ranging between not at all to very much) and a final question: 'Are you interested in a selfinstructive health profile, followed by a health dialogue, a blood pressure and blood sugar check?' The questionnaire was distributed at the reception desk to all individuals aged 18-79 attending the PCCs.

\section{Self-administered health profile-intervention} and assessment

This instrument has been described previously. ${ }^{16}$ The questionnaire, distributed by the health educator, was answered at home before the health dialogue consultation at the PCC. In our experience, this allows for $1 \mathrm{~h}$ of reflection, with individual variations. The results of the questionnaire were converted to a self-instructed health profile $(\mathrm{Hp})$ comprising eight variables. Six of these are classified as 'good', 'not so good' or 'risk' (corresponding to a green, yellow or red field, respectively). The self-instructive $\mathrm{Hp}$ was used to introduce a pedagogic component of reflection and motivational thoughts. Accordingly, the participants' own reflections are facilitated by immediate feedback when possibilities for lifestyle changes can be presented and contacts for further health dialogues can be offered. This was the second step in the intervention.

When using the instrument for assessment for baseline data and follow-up we used the dichotomised variable 'good' versus 'not so good/risk'. Two variables ('life ladder') deal with the perception of one's life situation present and in the future, measured with a visual analogue scale $(1-10,10=$ best $)$.

\section{Survey questions concerning leisure physical activity,} well-being and stress-level assessment

We used validated survey questions (sq) from the Gothenburg population studies. The leisure physical activity groups were classified as follows: 'low', 'intermediate', 'high' and 'very high' physical activity. ${ }^{17} 18$ The general well-being question was, 'How do you feel about your health situation (well-being)?". ${ }^{19}$ 20 A Likert-type scale ranging from 1 to 7 was used. The answers were rated from 'excellent, couldn't be better' (1) to 'very poor' (7). The variable 'well-being' was dichotomised so that 1-3 corresponded to 'good' and 4-7 corresponded to 'poor'.

Mental stress was assessed with a single-item questionnaire. ${ }^{21}{ }^{22}$ Mental stress was defined as feeling tense, irritable or anxious. The participants were asked to report how often they had felt stress using the following alternatives: 'never'; 'one period but not during the last 5 years'; 'one period during the last 5 years'; 'several periods during the last 5 years'; 'persistent stress during the last year'; and 'persistent stress during the last 5 years'. Baseline data resulted in a dichotomised variable, where the variable 'no stress' corresponded to 
'never felt stress' and 'one period but not during the last 5 years' and the variable 'period of stress' corresponded to 'one period during the last 5 years', 'several periods during the last 5 years', 'persistent stress during the last year' and 'persistent stress during the last 5 years'.

\section{Biological variables}

The following biological variables were measured: systolic and diastolic blood pressure, capillary p-glucose, weight, BMI, waist-hip ratio (WHR) and waist circumference. Systolic and diastolic blood pressures were measured in the right arm in the sitting position after $5 \mathrm{~min}$ rest. p-Glucose was measured in the 'non-fasting' state, since testing was integrated into the ordinary patient consultation. Weight was measured with light clothing and without shoes. BMI was calculated as weight/ height ${ }^{2}$. Waist circumference was measured in the standing position at the level midway between the lower rib margin and the iliac crest. Hip circumference was measured at the widest point between hip and buttock. WHR was calculated as waist circumference divided by hip circumference $(\mathrm{cm} / \mathrm{cm})$.

\section{Intervention}

The intervention consisted of (1) screening questionnaire, (2) the Hp and (3) the health dialogue.

\section{Health dialogue}

The dialogue emanated from the individual's responses to the Hp. If the individual stated interest this was offered and was performed in a salutogenic perspective by a health educator or district nurse. The dialogue lasted from $20 \mathrm{~min}$ to $1 \mathrm{~h}$, depending on the results in the profile protocol. At the end of the dialogue the patient, if necessary, had the opportunity to choose among different programmes designed to promote lifestyle change aided by multidisciplinary teams, to make these changes on his/her own-or to abstain.

The participant decided in concert with the health educator on way of lifestyle change and was offered relevant components in a broad programme on stop smoking, hazardous use of alcohol, stress management, promoting physical activity, sleep management programme and diet information within a health-promoting structured programme in the Hisingen primary healthcare area. The common goal was to strengthen the individual's own health-promoting activities and also participation in municipal and cultural facilities such as library activities, migrant associations and sports clubs.

\section{Statistical methods}

For comparison of differences between presumptive participants and non-participants in answering screening questions (affirmative, uncertain or negative), Pearson's $\chi^{2}$ test was used. Significance for gender differences among presumptive participants at baseline was tested by regression analyses. At 1-year follow-up we recorded improvement, deterioration and no change, compared to baseline. The respective numbers and percentages related to improvement and deterioration are shown. The paired samples t test was used for change in continuous variables, and the Wilcoxon matched-pair signed ranks test was chosen for change in categorical variables. Pearson $\chi^{2}$ test was used for testing differences between men and women. Logistic regression analysis test resulted in ORs and 95\% CI for men and women and for each variable, the OR for improvement is set at one for men, relative to which that for women is expressed.

\section{RESULTS}

Seventy per cent of the visitors to the PCC (22 554 patients) were reached by the waiting-room screening questionnaires, that is, the start of the intervention/reflection. Of the 11571 returned screening leaflets, 7789 $(67 \%)$ indicated motivation for lifestyle changes and consented to participate and thus formed the group of presumptive participants in the health dialogue. The remaining 3782 indicated no current motivation for lifestyle changes and thus represented presumptive non-participants.

\section{Comparison between presumptive participants and presumptive non-participants}

A higher percentage of presumptive participants reported a less favourable lifestyle, compared to presumptive non-participants (table 1). There were statistically significant differences between presumptive participants and presumptive non-participants in affirmative/uncertain/negative responses to all screening questions, except smoking, with indication of worse lifestyle and accordingly higher risk of developing risk factors and future illness in presumptive participants. Testing separately for affirmative and negative answers revealed significant differences, except in smoking, mental stress at work and too much alcohol. Figure 1 also shows that the presumptive participants indicated higher motivation and more readiness to initiate lifestyle change $(p<0.001)$.

\section{Participation and baseline data}

Of the presumptive participants, 3691(47\%) actually attended the first health dialogue at baseline and formed the group of participants at baseline (figure 2). Of these, 2120 (57\%) returned at follow-up, thereby completing the whole programme. The prevalence of risk, defined as one or more self-reported risk factor in the waiting-room screening questionnaire, was 96\% among presumptive participants. Only $1 \%$ of those wanting to participate reported no risk factor at all.

Table 2 shows baseline mean values for biological variables in the 3691 women and men who eventually chose to participate in the health dialogue in age cohorts, as well as the number and percentage with negative lifestyle factors based on $\mathrm{Hp}$, sq and family history of 
Table 1 Comparison between presumptive participants and non-participants concerning the frequency of affirmative (Yes), uncertain (Don't know) and negative (No) answers to the screening questions

\begin{tabular}{|c|c|c|c|c|c|c|c|c|c|}
\hline & \multirow{2}{*}{\multicolumn{3}{|c|}{$\begin{array}{l}\text { Presumptive participants } n(\%) \\
\text { of } n=7789 \\
n(\%)\end{array}$}} & \multicolumn{3}{|c|}{$\begin{array}{l}\text { Presumptive non-participants } \\
n(\%) \text { of } n=3782\end{array}$} & \multicolumn{3}{|c|}{ p Values } \\
\hline & & & & & & & & Yes & \\
\hline & Yes & $\begin{array}{l}\text { Don't } \\
\text { know }\end{array}$ & No & Yes & $\begin{array}{l}\text { Don't } \\
\text { know }\end{array}$ & No & Overall & $\begin{array}{l}\text { +Don't } \\
\text { know/No }\end{array}$ & $\begin{array}{l}\text { Yes/ } \\
\text { No }\end{array}$ \\
\hline $\begin{array}{l}\text { Too little physical } \\
\text { activity } N=11371\end{array}$ & $4057(53)$ & $1058(14)$ & 2559 (33) & $1811(49)$ & $332(9)$ & $1554(42)$ & $<0.001$ & $<0.001$ & $<0.001$ \\
\hline Smoking $N=11459$ & $1968(25)$ & - & $5755(75)$ & $988(26)$ & - & $2748(74)$ & 0.269 & - & 0.269 \\
\hline $\begin{array}{l}\text { Mental stress at work } \\
\mathrm{N}=10827\end{array}$ & $3579(50)$ & $438(6)$ & $3219(44)$ & $1782(49)$ & $168(5)$ & $1641(46)$ & 0.012 & 0.233 & 0.574 \\
\hline $\begin{array}{l}\text { Mental stress during } \\
\text { leisure time } \mathrm{N}=11356\end{array}$ & $3180(42)$ & $500(6)$ & 3977 (52) & $1293(35)$ & $187(5)$ & $2219(60)$ & $<0.001$ & $<0.001$ & $<0.001$ \\
\hline $\begin{array}{l}\text { Too much alcohol } \\
\mathrm{N}=11144\end{array}$ & $688(9)$ & $488(7)$ & $6312(84)$ & $335(9)$ & 175 (5) & $3146(86)$ & 0.001 & 0.015 & 0.739 \\
\hline Overweight $\mathrm{N}=11503$ & $3574(46)$ & $685(9)$ & $3505(45)$ & $1264(34)$ & $193(5)$ & $2282(61)$ & $<0.001$ & $<0.001$ & $<0.001$ \\
\hline $\begin{array}{l}\text { Too much fat } \\
\mathrm{N}=11503\end{array}$ & 1455 (19) & $1732(22)$ & $4575(59)$ & $632(17)$ & $493(13)$ & $2616(70)$ & $<0.001$ & $<0.001$ & $<0.001$ \\
\hline $\begin{array}{l}\text { Too little fiber } \\
N=11478\end{array}$ & $1901(25)$ & $1874(24)$ & $3974(51)$ & $896(24)$ & $599(16)$ & $2234(60)$ & $<0.001$ & $<0.001$ & $<0.001$ \\
\hline $\begin{array}{l}\text { Too much sweet food } \\
\mathrm{N}=11474\end{array}$ & $2223(29)$ & $1112(14)$ & 4414 (57) & $992(26)$ & 325 (9) & $2408(65)$ & $<0.001$ & $<0.001$ & $<0.001$ \\
\hline $\begin{array}{l}\text { Family history of } \\
\text { cardio-vascular } \\
\text { disease } N=11468 \\
\end{array}$ & $4793(62)$ & 704 (9) & 2248 (29) & $1863(50)$ & $259(7)$ & 1601 (43) & $<0.001$ & $<0.001$ & $<0.001$ \\
\hline
\end{tabular}

cardiovascular disease. It should be emphasised that the mean waist circumference was $>100 \mathrm{~cm}$ for men in all age cohorts over 30 years and $>90 \mathrm{~cm}$ for women in all age cohorts over 40 years. For both genders in all age cohorts over 40 years, the mean BMI was $>27 \mathrm{~kg} / \mathrm{m}^{2}$. A high number of negative lifestyle factors were found in the younger age cohorts. More than one-third of men in

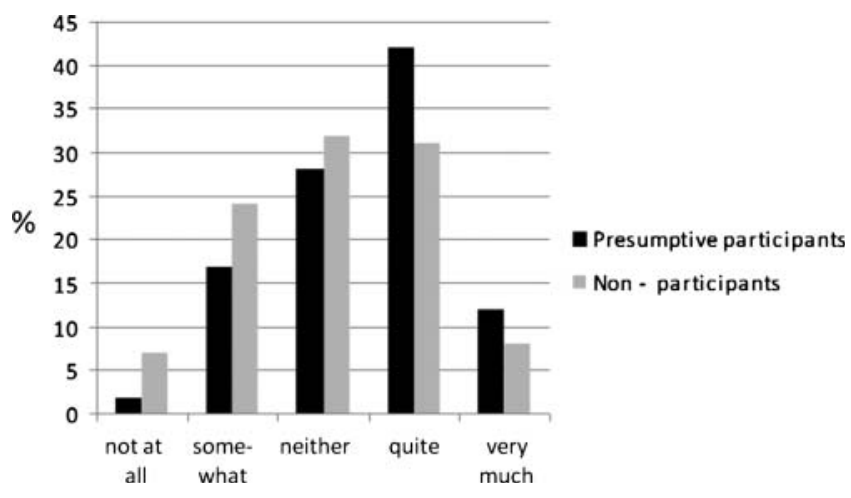

Figure 1 Differences between presumptive participants and non-participants concerning readiness to undertake lifestyle change. The responses, given in per cent, are to the screening question 'How ready are you to change your lifestyle right now based on your life situation?'. The participants exhibited more readiness to initiate lifestyle change, $\mathrm{p}<0.001$ (Pearson's $\chi^{2}$ test). the three youngest age cohorts were smokers and almost one-fourth of women in the same cohorts. Negative alcohol habits were seen for men in particular in the 50-59 years cohort and for women in the youngest age cohort. Low physical activity (Hp) was seen in the younger age cohorts especially among women. Mental stress (sq) was commonly reported particularly in young age cohorts. Poor well-being (sq) was expressed by more than $50 \%$ among women between 18 and 69 years of age and also reported by more than $40 \%$ among men. It is notable that reported negative lifestyle factors were common, particularly in the younger age cohorts and among women. The gender differences were significant for all variables except for BMI, diet (Hp), physical inactivity (sq) and view of life-future.

\section{Change from baseline at 1-year follow-up $(n=2120)$}

There were 2120 participants at the 1-year follow-up. Table 3 shows results for men, women and the total group. Women had significantly improved all biological variables after 1 year, compared to baseline. Men exhibited significant improvements in $\mathrm{BMI} \geq 30 \mathrm{~kg} / \mathrm{m}^{2}$, systolic and diastolic blood pressure and p-glucose the latter in cases exceeding $7 \mathrm{mmol} / \mathrm{l}$ at baseline. Significant positive changes were seen regarding smoking, alcohol habits, physical activity, strain and mental stress. Logistic regression analysis revealed a gender difference concerning WHR and physical 


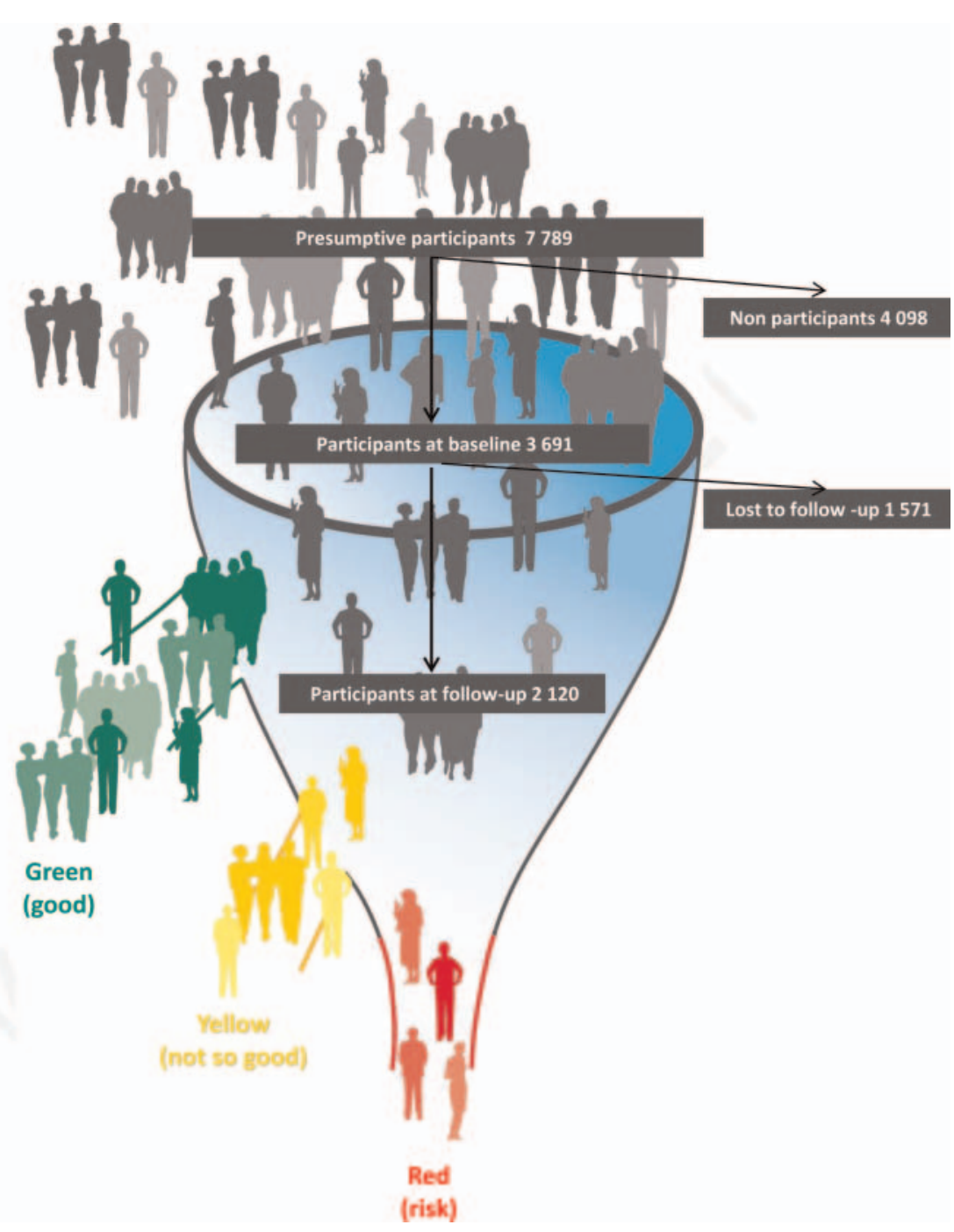

Figure 2 The funnel illustrates the selection process, based on the health profile, with gradually decreasing outflow for green (good), yellow (not so good) and red (risk). It also illustrates the dynamic process whereby the participants, following their own insight mediated through screening leaflets, are identified and offered a health dialogue.

activity, with women showing more pronounced improvement than men (table 4).

\section{DISCUSSION}

Our study confirms the findings in our pilot study ${ }^{16}$ that it was possible to reach motivated individuals with unhealthy lifestyles via a simple and swift screening questionnaire offering participation in a health-promotion programme. It was possible to reach the majority of PCC visitors with the first part of this intervention, that is, simple screening questions, highlighting the possibility of individual health promotion at the local PCC. Baseline data showed that negative lifestyle factors are common not least in younger age groups indicating need for intervention.

The strength of our study was first the setting in an ordinary primary care context with a large number of participants. Furthermore, the early intervention engaged the participant's own thoughts and motivation, which might have been facilitated by the extensive access to the waiting-room questionnaire, which could be perused and rejected anonymously. Third, the feasibility in a regular primary care context and the design allowed for knowledge transfer about structure and performance monitoring to the staff. The target group was unselected and not limited by research criteria, in order to achieve the primary goal of implementation of a simple healthpromoting strategy suited for primary healthcare. Moreover, the design permits long-term follow-up and the highly structured set-up should facilitate reproduction in other primary care settings. An important aspect of the stepwise design was to facilitate the individuals' own thinking in a context in which a more extensive health dialogue could be offered. A limitation was that this naturalistic and descriptive study was performed without a parallel control group. However, a randomised controlled trial in an ordinary primary care context is difficult to perform without 
Table 2 Baseline data from the total of 3691 participants and for men and women, respectively, according to age

\begin{tabular}{|c|c|c|c|c|c|c|c|c|c|c|c|c|c|c|c|}
\hline & \multirow{3}{*}{$\begin{array}{l}\frac{\text { Total }}{\text { Mean (SD) }} \\
\text { n=3691 }\end{array}$} & \multicolumn{6}{|l|}{ Men } & \multirow[t]{2}{*}{ Total men } & \multicolumn{6}{|l|}{ Women } & \multirow[t]{2}{*}{$\begin{array}{l}\text { Total } \\
\text { women }\end{array}$} \\
\hline & & \multicolumn{6}{|l|}{ Men (SD) } & & \multicolumn{6}{|l|}{ Mean (SD) } & \\
\hline & & $\begin{array}{l}18-29 \\
(n=95)\end{array}$ & $\begin{array}{l}30-39 \\
(n=185)\end{array}$ & $\begin{array}{l}40-49 \\
(n=196)\end{array}$ & $\begin{array}{l}50-59 \\
(n=241)\end{array}$ & $\begin{array}{l}60-69 \\
(n=363)\end{array}$ & $\begin{array}{l}70-79 \\
(n=203)\end{array}$ & $(n=1283)$ & $\begin{array}{l}18-29 \\
(n=225)\end{array}$ & $\begin{array}{l}30-39 \\
(n=365)\end{array}$ & $\begin{array}{l}40-49 \\
(n=445)\end{array}$ & $\begin{array}{l}50-59 \\
(n=470)\end{array}$ & $\begin{array}{l}60-69 \\
(n=579)\end{array}$ & $\begin{array}{l}70-79 \\
(n=320)\end{array}$ & $\begin{array}{l}\text { Total } \\
(n=2404)\end{array}$ \\
\hline Weight (kg) & $78.5(16.1)$ & $82.4(16.5)$ & $89.4(17.6)$ & $89.8(15.0)$ & $91.1(16.3)$ & $87.0(11.9)$ & $84.1(12.8)$ & $87.7(14.9)$ & $70.0(15.8)$ & $73.4(16.1)$ & $75.4(15.7)$ & $74.3(13.8)$ & 73.6 (13.1) & 72.4 (12.4) & $73.5(14.4)$ \\
\hline Waist circumference & $94.9(13.1)$ & $90.8(11.2)$ & $100.1(15.4)$ & $101.7(13.5)$ & $103.1(10.6)$ & $100.2(9.5)$ & $101.7(9.8)$ & $100.7(11.5)$ & $83.9(12.0)$ & $87.8(12.6)$ & $90.8(12.7)$ & $92.3(12.8)$ & $93.8(12.7)$ & $94.2(11.2)$ & $91.5(12.8)$ \\
\hline Body mass index & $27.3(4.8)$ & $25.3(4.6)$ & $27.6(4.9)$ & $28.0(4.3)$ & $28.5(4.5)$ & $27.6(3.7)$ & $27.1(3.9)$ & $27.6(4.3)$ & $25.1(5.3)$ & $26.7(5.6)$ & $27.6(5.3)$ & $27.6(5.1)$ & $27.3(4.8)$ & $27.5(4.5)$ & $27.2(5.1)$ \\
\hline Waist-hip ratio & $0.9(0.1)$ & $0.9(0.1)$ & $0.9(0.1)$ & $1.0(0.1)$ & $1.0(0.1)$ & $1.0(0.1)$ & $1.0(0.1)$ & $1.0(0.1)$ & $0.8(0.1)$ & $0.8(0.1)$ & $0.9(0.1)$ & $0.9(0.1)$ & $0.9(0.1)$ & $0.9(0.1)$ & $0.9(0.1)$ \\
\hline $\begin{array}{l}\text { Systolic blood } \\
\text { pressure }\end{array}$ & $127.2(18.8)$ & $118.6(10.3)$ & $122.4(13.6)$ & $127.2(15.8)$ & $132.7(16.8)$ & $135.0(17.2)$ & $139.0(17.2)$ & $131.0(17.2)$ & $111.4(10.8)$ & $112.7(12.6)$ & $118.0(14.8)$ & $126.8(17.5)$ & $134.4(19.5)$ & $140.0(18.5)$ & $125.2(19.3)$ \\
\hline Cap plsama glucose & $6.4(1.5)$ & $5.8(0.9)$ & $6.0(1.2)$ & $6.2(1.4)$ & $6.6(1.6)$ & $6.8(1.9)$ & $7.2(1.8)$ & $6.5(1.7)$ & $5.9(1.0)$ & $6.1(1.3)$ & $6.2(1.2)$ & $6.4(1.5)$ & $6.4(1.4)$ & $6.5(1.5)$ & $6.3(1.4)$ \\
\hline View of life-present & $6.3(2.0)$ & $5.7(1.7)$ & $6.0(1.7)$ & $5.9(2.1)$ & $6.2(1.8)$ & $7.1(1.8)$ & $7.3(1.7)$ & $6.5(1.9)$ & $5.6(1.7)$ & $5.6(1.9)$ & $5.7(1.9)$ & $6.1(2.0)$ & $6.6(2.0)$ & $7.0(2.0)$ & $6.2(2.0)$ \\
\hline \multirow[t]{2}{*}{ View of life-future } & $7.4(1.8)$ & $7.5(1.5)$ & $7.4(1.5)$ & $7.1(1.9)$ & $7.2(1.7)$ & $7.7(1.7)$ & $7.3(1.8)$ & $7.4(1.7)$ & $7.4(1.6)$ & $7.4(1.7)$ & $7.6(1.6)$ & $7.6(1.7)$ & $7.5(1.9)$ & $7.3(1.9)$ & $7.5(1.8)$ \\
\hline & $n(\%)$ & & & & & & & & & & & & & & \\
\hline Smoking (Hp) & $800(22)$ & $38(40)$ & $67(36)$ & $70(36)$ & $74(31)$ & $84(23)$ & $19(9)$ & $352(27)$ & $62(28)$ & $75(21)$ & $107(24)$ & $94(20)$ & $93(16)$ & $16(5)$ & $447(19)$ \\
\hline Alcohol (Hp) & 450 (12) & $22(23)$ & $34(18)$ & $35(18)$ & $64(27)$ & $78(22)$ & 24 (12) & $257(20)$ & $37(16)$ & $15(4)$ & $39(9)$ & 36 (8) & $50(9)$ & $15(5)$ & $192(8)$ \\
\hline Diet $(\mathrm{Hp})$ & $2143(58)$ & $63(66)$ & $139(75)$ & $123(63)$ & $143(59)$ & $178(49)$ & $100(49)$ & $746(58)$ & $148(66)$ & $247(68)$ & $288(65)$ & $252(54)$ & $296(51)$ & $166(52)$ & $1397(58)$ \\
\hline Physical activity $(\mathrm{HP})$ & $2512(68)$ & $57(60)$ & $133(72)$ & $141(72)$ & $171(71)$ & $188(52)$ & $104(51)$ & $794(62)$ & $169(75)$ & 297 (82) & $337(76)$ & $332(71)$ & $378(65)$ & $203(63)$ & $1716(71)$ \\
\hline $\begin{array}{l}\text { Living conditions } \\
\text { (Hp) }\end{array}$ & $1099(30)$ & 31 (33) & $67(36)$ & $80(41)$ & $80(33)$ & 42 (12) & $12(6)$ & $312(24)$ & $103(46)$ & $173(47)$ & $202(45)$ & $183(39)$ & 97 (17) & $28(9)$ & $786(33)$ \\
\hline Stress (Hp) & $1037(28)$ & $25(26)$ & $51(28)$ & $61(31)$ & $56(23)$ & $35(10)$ & $14(7)$ & $242(19)$ & $109(48)$ & $168(46)$ & $191(43)$ & $153(33)$ & $126(22)$ & $47(15)$ & 794 (33) \\
\hline Period of stress(sq) & 2694 (73) & $73(77)$ & $155(84)$ & $165(84)$ & $171(71)$ & $185(51)$ & $53(26)$ & $802(63)$ & $203(90)$ & $330(90)$ & $402(90)$ & $389(83)$ & $411(71)$ & $154(48)$ & $1889(79)$ \\
\hline Family history (yes) & 2377 (64) & $41(43)$ & $92(50)$ & $121(62)$ & $159(66)$ & $212(58)$ & $114(56)$ & $739(58)$ & $109(48)$ & $210(58)$ & $318(72)$ & $359(76)$ & $413(71)$ & 226 (71) & 1635 (68) \\
\hline \multicolumn{16}{|c|}{$\begin{array}{l}\text { Biological variables: continuous variables are presented as mean and SD. The categorical variable view of life (10 steps) is presented as mean and SD. The six categorical variables from the health profile (Hp) corresponding to not so } \\
\text { good/risk are given as number and percent (n(\%)). The variable well-being is dichotomised and 'poor' corresponds to the scale ranging from 'neither good nor bad to very poor' (4-7). The variable physical inactivity corresponds to } \\
\text { 'inactive'. The variable stress is dichotomised and corresponds to 'one period during the last } 5 \text { years' and 'several periods during the last } 5 \text { years' and 'persistent stress during the last year' and 'persistent stress during the last } 5 \text { years'. } \\
\text { Family history of cardio-vascular disease corresponds to 'yes' response to the screening questions. Sq, survey questions. }\end{array}$} \\
\hline
\end{tabular}


Table 3 Change in health variables at 1-year follow-up compared to baseline $(n=2120)$

\begin{tabular}{|c|c|c|c|c|c|c|}
\hline \multirow[b]{2}{*}{ Continuous variables } & \multicolumn{2}{|c|}{ Total $(n=2120)$} & \multicolumn{2}{|l|}{ Men $(n=730)$} & \multicolumn{2}{|c|}{ Women $(n=1390)$} \\
\hline & $\begin{array}{l}\text { Mean (SD) } \\
\text { reduction }\end{array}$ & p Value & $\begin{array}{l}\text { Mean (SD) } \\
\text { reduction }\end{array}$ & $p$ Value & Mean (SD) & p Value \\
\hline Weight (kg) (n=2104) & $0.34(4.0)$ & $<0.001$ & $0.28(4.08)$ & 0.069 & $0.38(3.9)$ & $<0.001$ \\
\hline BMI $\left(\mathrm{kg} / \mathrm{m}^{2}\right)(\mathrm{n}=2082)$ & $0.08(1.6)$ & 0.015 & $0.007(1.69)$ & 0.913 & $0.12(1.5)$ & 0.002 \\
\hline$B M I \geq 25\left(\mathrm{~kg} / \mathrm{m}^{2}\right) \quad(\mathrm{n}=1420)$ & $0.2(1.8)$ & $<0.001$ & $0.065(1.88)$ & 0.425 & $0.287(1.71)$ & $<0.001$ \\
\hline$B M I \geq 30\left(\mathrm{~kg} / \mathrm{m}^{2}\right)(\mathrm{n}=533)$ & $0.49(2.0)$ & $<0.001$ & $0.378(1.78)$ & 0.006 & $0.548(2.07)$ & $<0.001$ \\
\hline Waist circumference $(\mathrm{cm})(\mathrm{n}=1064)$ & $0.78(5.0)$ & $<0.001$ & $0.47(5.11)$ & 0.070 & $0.961(4.88)$ & $<0.001$ \\
\hline WHR (n=2034) & $0.004(0.05)$ & $<0.001$ & $0.002(0.046)$ & 0.245 & $0.006(0.045)$ & $<0.001$ \\
\hline Systolic blood pressure $(\mathrm{mm} \mathrm{Hg})(n=2090)$ & $1.03(15.0)$ & 0.002 & $1.24(14.6)$ & 0.023 & 0.918(15.19) & 0.026 \\
\hline Systolic blood pressure $(\mathrm{mm} \mathrm{Hg}) \geq 140(\mathrm{n}=648)$ & $9.4(16.8)$ & $<0.001$ & $8.33(15.53)$ & $<0.001$ & $10.018(17.55)$ & $<0.001$ \\
\hline Diastolic blood pressure $(\mathrm{mm} \mathrm{Hg})(\mathrm{n}=2087)$ & $0.93(9.9)$ & $<0.001$ & $1.16(8.8)$ & $<0.001$ & $0.809(10.41)$ & 0.004 \\
\hline Diastolic blood pressure $(\mathrm{mm} \mathrm{Hg}) \geq 90(n=366)$ & 8.7(11.0) & $<0.001$ & $6.8(8.09)$ & $<0.001$ & $10.12(12.60)$ & $<0.001$ \\
\hline Cap p-glucose $(\mathrm{mmol} / \mathrm{l})(\mathrm{n}=1986)$ & $0.13(1.5)$ & $<0.001$ & $0.107(1.78)$ & 0.119 & $0.139(1.38)$ & $<0.001$ \\
\hline Cap p-glucose $(\mathrm{mmol} / \mathrm{l}) \geq 7(\mathrm{n}=454)$ & $1.2(2.1)$ & $<0.001$ & $1.09(2.42)$ & $<0.001$ & $1.323(1.75)$ & $<0.001$ \\
\hline Categorical variables & $\mathrm{n}(\%)$ & p Value & $\mathrm{n}(\%)$ & p Value & $n(\%)$ & p Value \\
\hline Smoking $(H p)(n=2106)$ & $90(4)$ & $<0.001$ & $42(6)$ & $<0.001$ & $48(4)$ & $<0.001$ \\
\hline Alcohol (Hp) $(n=2104)$ & $120(6)$ & $<0.001$ & 64(9) & $<0.001$ & $56(4)$ & $<0.001$ \\
\hline Diet $(\mathrm{Hp})(\mathrm{n}=2098)$ & $480(23)$ & $<0.001$ & 164(23) & $<0.001$ & $316(23)$ & $<0.001$ \\
\hline Physical activity(Hp) (n=2091) & $364(17)$ & $<0.001$ & $97(14)$ & 0.004 & $267(19)$ & $<0.001$ \\
\hline Living conditions $(H p)(n=1786)$ & $247(14)$ & $<0.001$ & $65(11)$ & 0.020 & $182(16)$ & $<0.001$ \\
\hline Stress $(H p)(n=2103)$ & 234(11) & $<0.001$ & $54(7)$ & 0.004 & $180(13)$ & $<0.001$ \\
\hline Well-being (sq) $(n=2062)$ & $382(19)$ & $<0.001$ & $115(16)$ & 0.003 & $267(20)$ & $<0.001$ \\
\hline Physical activity (sq) $(n=2060)$ & $219(11)$ & $<0.001$ & $72(10)$ & $<0.001$ & $147(11)$ & $<0.001$ \\
\hline Period of stress (sq) $(n=2066)$ & $544(26)$ & $<0.001$ & $181(26)$ & 0.040 & $363(27)$ & $<0.001$ \\
\hline View of life present $(H p)(n=2047)$ & 791 (39) & $<0.001$ & $264(38)$ & 0.002 & $527(39)$ & $<0.001$ \\
\hline View of life future $(H p)(n=2010)$ & $661(33)$ & 0.001 & $212(31)$ & 0.340 & $449(34)$ & 0.002 \\
\hline
\end{tabular}

Continuous variables (weight, body mass index (BMI), waist circumference, waist-hip ratio (WHR), blood pressure and p-glucose) are shown as reduction in mean and SD. The categorical variables: six from the health profile (Hp), three from the survey questions (sq) on well-being, physical activity and stress and two on view of life $(\mathrm{Hp})$ are shown as number improved $\mathrm{n}(\%)$. Response rate varies due to missing values

losing the main aim of wide implementation. Limitations of randomised controlled studies have been discussed in relation to population-based interventions. ${ }^{23}$ Comparison with another primary healthcare area in Gothenburg would not have been valid and would have generated confounders such as differences in population and case mix, as well as variations in primary healthcare processes. A further limitation was the participants' access to the baseline protocol; we cannot completely rule out that some participants might have remembered the results of their first

Table 4 The change is shown as improvement or deterioration from baseline to 1-year follow-up $(n=2120)$ with respect to the following variables: body mass index (BMI), waist-hip ratio (WHR), waist circumference, p-glucose, systolic and diastolic blood pressure, smoking and alcohol habits, physical activity and stress

\begin{tabular}{|c|c|c|c|c|c|c|c|}
\hline \multirow[b]{3}{*}{ Variables } & \multicolumn{2}{|l|}{ Change men } & \multicolumn{2}{|c|}{ Change women } & \multirow{3}{*}{$\mathbf{p}$} & \multicolumn{2}{|c|}{ Women } \\
\hline & \multicolumn{2}{|l|}{$\mathrm{n}(\%)$} & \multirow[b]{2}{*}{ Improvement } & \multirow[b]{2}{*}{ Deterioration } & & & \\
\hline & Improvement & Deterioration & & & & OR & $95 \% \mathrm{Cl}$ \\
\hline BMI $(n=1801)$ & $315(51)$ & $304(49)$ & $630(53)$ & $552(47)$ & 0.331 & 0.88 & 0.72 to 1.07 \\
\hline WHR $(n=1699)$ & $311(53)$ & $277(47)$ & $650(58.5)$ & $461(41.5)$ & 0.026 & 0.80 & 0.66 to 0.98 \\
\hline Waist circumference $(n=910)$ & $180(55)$ & $149(45)$ & $339(58)$ & $242(42)$ & 0.287 & 0.85 & 0.65 to 1.12 \\
\hline p-Glucose $(n=1917)$ & $360(55)$ & $292(45)$ & $703(56)$ & $562(44)$ & 0.881 & 0.98 & 0.81 to 1.18 \\
\hline Systolic blood pressure $(n=1717)$ & $327(55)$ & $269(45)$ & $584(52)$ & $537(48)$ & 0.274 & 1.11 & 0.91 to 1.36 \\
\hline Diastolic blood pressure $(n=1619)$ & $327(57)$ & $243(43)$ & $574(55)$ & $475(45)$ & 0.305 & 1.11 & 0.90 to 1.36 \\
\hline Smoking $(H p)(n=126)$ & $42(76)$ & $13(24)$ & $51(72)$ & $20(28)$ & 0.566 & 1.31 & 0.58 to 2.96 \\
\hline Alcohol $(H p)(n=194)$ & $79(71)$ & 32 (29) & $65(78)$ & $18(22)$ & 0.260 & 0.71 & 0.36 to 1.39 \\
\hline Physical activity (Hp) (n=757) & $148(63.5)$ & $85(36.5)$ & $385(73.5)$ & $139(26.5)$ & 0.006 & 0.64 & 0.46 to 0.89 \\
\hline Stress $(H p)(n=361)$ & $57(64)$ & $32(36)$ & $190(70)$ & $82(30.1)$ & 0.306 & 0.77 & 0.46 to 1.27 \\
\hline
\end{tabular}

Pearson $\chi^{2} p$ values for differences between men and women are shown. The OR shows differences between men and women with age adjustment with men as reference $(\mathrm{OR}=1)$. Hp, health profile. 
report. The biological variables were generally measured by the same staff at baseline and follow-up in order to increase reliability, but some degree of bias cannot be ruled out. The response rate of $67 \%$ was adequate, based on our previous experiences with questionnaires.

The goal of reaching both the majority of visitors with a health-promoting intervention and of sifting out both individuals with risk factors, and the few but important individuals at high risk was achieved, illustrated by a funnel (figure 2). Thus, only $4 \%$ of the participants at baseline were referred to their GPs in order to benefit from a high-risk prevention strategy and secondary prevention. Patients at high risk might benefit more from consultation with a GP, while others do well with health educators. ${ }^{24}$ Most of the participants started lifestyle changes with or without coaching. The improvement found at the 1-year follow-up was considered a result of this method that utilised the individual's resources and in which the staff acted more as coaches than therapists. The results also confirmed our earlier report on selfassessment by screening questions and improvement in physical activity and mental stress after 1 year. ${ }^{16}$ Interestingly, we found that women were more successful than men when it came to change in WHR and physical activity. Gender differences in lifestyle improvement have been discussed to less extent in the literature. Weight loss interventions have been tested predominantly in female samples, ${ }^{25}$ while action plans for changing and social support differ between the genders in other studies. ${ }^{26}$

The results of our method were compatible with those of large well-designed studies in other contexts, in which participants from the population were offered checkups, based on specified criteria. ${ }^{27-29}$ We, however, used the primary care arena for all applicants in a naturalistic context to initiate behavioural change, in a pedagogical, self-monitoring low-budget model. On the basis of the knowledge of different stages of behavioural changes we assume that our screening questions make people prepared for such changes. ${ }^{30}$ Accordingly, in some cases individuals may start a change process themselves, others may be more susceptible to take part in available programmes for lifestyle intervention. GPs' knowledge and attitudes have previously been reported to be important for this type of work. ${ }^{31}$

Individuals with risk factors attending PCCs should be informed about the possibility of voluntary, personalised preventive consultation. However, only those motivated to change their lifestyle should be further engaged in the process, resulting in the most efficient use of the PCC's resources. It is our impression that knowledge about possible gender differences in the efficacy of lifestyle interventions is limited.

In conclusion, the preventive primary healthcare programme involved individuals motivated for as well as in need of, lifestyle changes to a major extent. Improvement concerning several risk factors was observed at 1-year follow-up, more so among women than men when it came to WHR and physical activity. The results are promising regarding possibility to implement a programme in primary care but long-term effects must be interpreted with caution as the study lacks a control group. The method is feasible for clinical use and for further studies of long-term results.

Acknowledgements We wish to thank the following partners. The study was initiated by extensive co-operation between the Hisingen/Gothenburg Health Care Organization and Health and Medical Services Board11. We also want to thank all managers and staff of the PCCs for their commitment, as well as the health educators at the PCCs: Lena Arvidsson, Johanna Davidsson, Andreas Fors, Farideh Jam, Elin Johansson, Jenny Krivanek, Lisa Lind, Gertrud Olsson and Anna Wågdahl.

Contributors $A B$ conceived and developed the method and study design and was responsible for the process in the primary care context, data collection, interpretation of the data and writing of the manuscript. NA contributed to the statistical analyses, interpretation of analyses and writing of the paper. A-CB contributed to the infrastructure of the project, study design and the process in the primary care context and production of the manuscript. BMF-F contributed to the process in the primary care context, data collection, interpretation of data and production of the manuscript. JT contributed to study design, the scientific analyses and writing of the manuscript. $C B$ contributed to the study design, scientific analyses and data interpretation, and writing of the manuscript and is the guarantor of the study.

Funding The study was funded by Primary Care Västra Götaland Region, Primary Care Gothenburg, and the Swedish Council for Working Life and Social Research grant no 2007-1958 (WISH project).

\section{Competing interests None.}

Ethics approval The study was approved by the Regional Ethical Review Board at the University of Gothenburg, Sweden.

Provenance and peer review Not commissioned; externally peer reviewed.

Data sharing statement Unpublished data from the study is still under preparation for further publication.

\section{REFERENCES}

1. Blair SN. Physical inactivity: the biggest public health problem of the 21st century. Br J Sports Med 2009;43:1-2.

2. Healy GN, Matthews CE, Dunstan DW, et al. Sedentary time and cardio-metabolic biomarkers in US adults: NHANES 2003-06. Eur Heart J 2011;32:590-7.

3. Finucane MM, Stevens GA, Cowan MJ, et al. National, regional, and global trends in body-mass index since 1980: systematic analysis of health examination surveys and epidemiological studies with 960 country-years and 9.1 million participants. Lancet 2011;377:557-67.

4. Bjorkelund C, Andersson-Hange D, Andersson $\mathrm{K}$, et al. Secular trends in cardiovascular risk factors with a 36-year perspective: observations from 38- and 50-year-olds in the Population Study of Women in Gothenburg. Scand J Prim Health Care 2008;26:140-6.

5. Wilhelmsen L, Welin L, Svardsudd K, et al. Secular changes in cardiovascular risk factors and attack rate of myocardial infarction among men aged 50 in Gothenburg, Sweden. Accurate prediction using risk models. J Intern Med 2008;263:636-43.

6. Berg C, Rosengren A, Aires N, et al. Trends in overweight and obesity from 1985 to 2002 in Goteborg, West Sweden. Int J Obes (Lond) 2005;29:916-24.

7. The National Board of Health and Welfare. http://www. socialstyrelsen.se/nationalguidelines (accessed June 2012).

8. Wang YC, McPherson $\mathrm{K}$, Marsh T, et al. Health and economic burden of the projected obesity trends in the USA and the UK. Lancet 2011;378:815-25.

9. Pessah-Rasmussen H, Engstrom G, Jerntorp I, et al. Increasing stroke incidence and decreasing case fatality, 1989-1998: a study from the stroke register in Malmo, Sweden. Stroke 2003;34:913-18.

10. Holmgren K, Dahlin-Ivanoff S, Bjorkelund C, et al. The prevalence of work-related stress, and its association with self-perceived health and sick-leave, in a population of employed Swedish women. BMC Public Health 2009;9:73. 
11. Lissner L, Sjoberg A, Schutze M, et al. Diet, obesity and obesogenic trends in two generations of Swedish women. Eur J Nutr 2008;47:424-31.

12. Blomstrand $\mathrm{A}$, Bjorkelund $\mathrm{C}$, Ariai $\mathrm{N}$, et al. Effects of leisure-time physical activity on well-being among women: a 32-year perspective. Scand J Public Health 2009;37:706-12.

13. Marmot M, Friel S, Bell R, et al. Closing the gap in a generation: health equity through action on the social determinants of health. Lancet 2008;372:1661-9.

14. Bjorkelund C, Lissner L, Devine C, et al. Long-term effects of a primary health care intervention program for women lower blood pressure and stable weight. Fam Med 2000; 32:246-51.

15. Rose GA. Rose's strategy of preventive medicine: the complete original text / Geoffrey Rose with a commentary by Kay-Tee Khaw, Michael Marmot, 2008.

16. Blomstrand A, Lindqvist P, Carlsson IE, et al. Low-budget method for lifestyle improvement in primary care. Experiences from the Goteborg Health Profile Project. Scand J Prim Health Care 2005;23:82-7.

17. Saltin B, Grimby G. Physiological analysis of middle-aged and old former athletes. Comparison with still active athletes of the same ages. Circulation 1968;38:1104-15.

18. Bengtsson C. Physical activity in a population sample of women and in women with ischaemic heart disease. Acta Med Scand Suppl 1973:93-6.

19. Tibblin G, Tibblin B, Peciva S, et al. "The Goteborg quality of life instrument"- an assessment of well-being and symptoms among men born 1913 and 1923. Methods and Validity. Scand J Prim Health Care Suppl 1990;1:33-8.

20. Sullivan M, Karlsson J, Bengtsson C, et al. "The Goteborg Quality of Life Instrument"-a psychometric evaluation of assessments of symptoms and well-being among women in a general population. Scand J Prim Health Care 1993;11:267-75.
21. Harmsen $P$, Rosengren A, Tsipogianni A, et al. Risk factors for stroke in middle-aged men in Goteborg, Sweden. Stroke 1990;21:223-9.

22. Rosengren A, Tibblin G, Wilhelmsen L. Self-perceived psychological stress and incidence of coronary artery disease in middle-aged men. Am J Cardiol 1991;68:1171-5.

23. Sanson-Fisher RW, Bonevski B, Green LW, et al. Limitations of the randomized controlled trial in evaluating population-based health interventions. Am J Prev Med. 2007;33:155-61.

24. Fleming P, Godwin M. Lifestyle interventions in primary care: systematic review of randomized controlled trials. Can Fam Physician 2008;54:1706-13.

25. Pagoto SL, Schneider KL, Oleski JL, et al. Male inclusion in randomized controlled trials of lifestyle weight loss interventions. Obesity (Silver Spring) 2011;20:1234-9.

26. Hankonen N. Psychosocial processes of health behaviour change in a lifestyle intervention Influences of gender, socioeconomic status and personality. Dissertation National institute for Health and Welfare, Helsinki, Finland, 2011.

27. Ketola E, Makela M, Klockars M. Individualised multifactorial lifestyle intervention trial for high-risk cardiovascular patients in primary care. Br J Gen Pract 2001;51:291-4.

28. Weinehall L, Hellsten G, Boman K, et al. Prevention of cardiovascular disease in Sweden: the Norsjo community intervention programme-motives, methods and intervention components. Scand J Public Health Supp/ 2001;56:13-20.

29. Lingfors $\mathrm{H}$, Lindstrom K, Persson LG, et al. Lifestyle changes after a health dialogue. Results from the Live for Life health promotion programme. Scand J Prim Health Care 2003;21:248-52.

30. Prochaska JO, DiClemente CC, Norcross JC. In search of how people change. Applications to addictive behaviors. Am Psychol 1992;47:1102-14.

31. Ampt AJ, Amoroso C, Harris MF, et al. Attitudes, norms and controls influencing lifestyle risk factor management in general practice. BMC Fam Pract 2009;10:59. 